\title{
3 \\ Developing a Planning-Level System-Wide Model using SWMM
}

\section{Khalid N. Khan and Terry J. Meeneghan}

The Allegheny County Sanitary Authority (ALCOSAN) is in the process of developing and implementing a Regional Long Term Wet Weather Control Concept Plan (RLTWWCCP) to control combined sewer overflow (CSO) and separate sewer overflow (SSO) discharges into receiving water bodies. The total cost of implementing this plan is estimated to be between US\$2 and US\$3 billion spread over the next 50 years. ALCOSAN and the participating municipalities hope to reduce this cost by refining the design of conveyance and control facilities, which can be achieved by better characterizing the hydraulic and hydrologic responses of the service area during the development stages of the RLTWWCCP. In order to develop and evaluate alternative conveyance measures and control facilities to manage the amount and frequency of CSO and SSO discharges, ALCOSAN has developed detailed hydraulic and hydrologic computer simulation models. These models have been and will be used to quantify the amount of flow that needs to be conveyed and treated by ALCOSAN and supplement the decision making process by evaluating various alternative solutions and help choose the most viable and cost effective solution.

ALCOSAN is a large authority, and development of the models requires a large level of effort, a considerable cost investment, and a long period of time. ALCOSAN's strategy has been a long-term approach where the level of model complexity increases with the level of detail and refinement needed

Khan, K. and T. Meeneghan. 2007. "Developing a Planning-Level System-Wide Model using SWMM." Journal of Water Management Modeling R227-03. doi: 10.14796/JWMM.R227-03.

(C) CHI 2007 www.chijournal.org ISSN: 2292-6062 (Formerly in Contemporary Modeling of Urban Water Systems. ISBN: 0-9736716-3-7) 
for planning and design. When model support for concept planning was needed to consider and evaluate numerous alternatives for control strategies, a simplified model was used which provided short run times and quick turnaround for the screening process. When model support for preliminary planning was needed to refine selected alternatives, additional model complexity was added. When detailed facility planning commences to optimize selected conveyance, storage and satellite treatment facilities, the required model complexity will be added. This tiered or incremental approach to model development satisfies the changing needs of large-scale planning projects during the entire project period, answering questions as they arise throughout the life of the project (Smullen et al., 2002).

In order to develop and implement a successful long term or short term $\mathrm{CSO}$ and SSO control plan, it is imperative to quantify and characterize the flow that needs to be conveyed and treated. As part of implementing the RLTWWCCP, ALCOSAN is evaluating the need to increase its current treatment capacity. To help quantify the volume and peak wet weather flow that can be conveyed to the ALCOSAN waste water treatment plant (WWTP) with the future RLTWWCCP conveyance improvements in place, a simplified planning level system-wide model was developed. The level of complexity and detail in the model was governed by the specific needs of the planning study.

While developing the simplified preliminary planning system-wide model a highly refined level of detail was used to quantify and characterize the amount of flow entering the conveyance system, during both dry weather and wet weather conditions. The simplification was in the reduction of the complexity of the hydraulic elements of the system which allowed increasing the simulation time step from 5 seconds to 60 seconds without computational instability. The simplified preliminary planning system-wide model was used to simulate long-term system response under various WWTP wet-well operational configurations. The simulation results provided ALCOSAN with information necessary to proceed with the refinement of the RLTWWCCP in terms of increasing the treatment capacity of the plant and mitigating the CSO and SSO discharges into the area water bodies.

This chapter describes the development of the simplified preliminary planning system-wide model, the validation effort and presentation of the model simulation results. The chapter also shows how the level of model complexity, and the corresponding level of effort and cost, were matched to the specific needs of the planning study. 


\subsection{Background Information}

\subsubsection{The ALCOSAN Authority}

The Allegheny County Sanitary Authority provides conveyance and treatment for sanitary and wet-weather flow to the City of Pittsburgh and all or part of 82 regional municipalities. The service area spans approximately $300 \mathrm{mi}^{2}\left(780 \mathrm{~km}^{2}\right)$ with a service population of 939,000 people based on the 2000 census. The conveyance system comprises approximately $90 \mathrm{mi}$. $(144 \mathrm{~km})$ of interceptor sewer, which includes approximately $30 \mathrm{mi} .(48 \mathrm{~km})$ of deep tunnel interceptors, at a depth of 20-175 ft (6-53 m.) below ground, primarily in the $80-100 \mathrm{ft}(24-30 \mathrm{~m})$ range) and approximately $60 \mathrm{mi}$. $(96 \mathrm{~km})$ of shallow-cut interceptors. The present secondary treatment capacity of the waste-water treatment plant is approximately 225 million gallons per day (mgd) (850 million liters per day). About 300 regulator structures along the interceptor sewers intercept the dry weather flow and control the wet-weather flow into the ALCOSAN conveyance system. ALCOSAN does not have jurisdiction over the local collection systems, which are owned and operated by the regional municipalities.

In order to control the frequency and amount of CSO and SSO discharges into the regional water bodies, ALCOSAN is in the process of refining and implementing a RLTWWCCP. The regional water bodies receiving ALCOSAN discharges are the three main rivers Allegheny, Monongahela and Ohio, and four tributaries Chartier's Creek, Saw Mill Run, Thompson Run and Turtle Creek. The water quality issues for ALCOSAN are those typically associated with urban wet weather discharges. The total cost of implementing this control plan is estimated to be as high as US $\$ 3$ billion. Approximately US $\$ 2$ billion would be invested within the first 15-20 y of implementation and the remainder would be spread over a subsequent 30-35 y period. ALCOSAN and the participating municipalities hope to reduce this cost by working together to refine the design of conveyance and control facilities, by better characterizing the hydraulic and hydrologic responses of the area under the RLTWWCCP.

\subsubsection{Study Area Description}

The ALCOSAN service area covers a significant part of Allegheny County located in south-western Pennsylvania. Approximately $20 \%\left(60 \mathrm{mi}^{2}\right.$ or $\left.156 \mathrm{~km}^{2}\right)$ of the service area is served by combined sewers, $47 \%\left(141 \mathrm{mi}^{2}\right.$ or $\left.367 \mathrm{~km}^{2}\right)$ is served by separate sewers and $33 \%\left(99 \mathrm{mi}^{2}\right.$ or $\left.257 \mathrm{~km}^{2}\right)$ is 
non-contributing due to non-development or on-site systems. The area is characterized by rounded hills and steep ridges which reach elevations approximately 1,200 ft (366 m) above mean sea-level. Soils are influenced by land use, which in the service area is characterized by intensely developed industrial, commercial and residential areas. Most of the original soils have been covered and altered by development. The steep terrain and highly urbanized areas result in rapid runoff responses to rainfall events. Therefore, runoff in the service area is characterized predominantly by short, high-intensity storm flows.

\subsection{Data Sources}

\subsubsection{Precipitation Data}

A gauge-adjusted radar-rainfall system was implemented in April 2000 to monitor precipitation within the Greater Pittsburgh region. The system is owned and operated by the 3 Rivers Wet Weather Demonstration Program (3RWWDP), a regional non-profit organization that made the investment to implement the system with the belief that improved precipitation estimates could significantly reduce the ultimate cost of regulatory compliance. The radar-rainfall system uses a geo-referenced $1 \mathrm{~km}^{2}$ pixel grid with 872 pixels required to cover the service area and 2,313 pixels needed to provide coverage to the entire Allegheny county. The system is currently supported by a network of 33 heated precipitation gauges installed at an average density of one gauge per $15 \mathrm{mi}^{2}\left(40 \mathrm{~km}^{2}\right)$. The radar-rainfall system provides continuous coverage in $15 \mathrm{~min}$ time steps for storms meeting specified minimum criteria for intensity and total depth. For storms meeting the specified criterion, radar based precipitation data is provided for each pixel. For small storms not meeting the defined criteria, each radar-rainfall pixel file is filled with gauge data using the inverse-distance method to provide a continuous precipitation record. The precipitation data is provided to engineers, municipalities, and other interested individuals via a web-site maintained by 3 RWWDP.

Orographic influences on rainfall patterns in the Pittsburgh area were found to be significant. If the ALCOSAN service area was flat and if rainfall tended to be relatively uniform, then refinements to the precipitation monitoring may not be needed. However the terrain within the Pittsburgh area is highly variable and storm fronts tend to be greatly influenced as they 
pass over the Allegheny range. The improved resolution of the precipitation data and the corresponding improvement to the model simulations provided by the high-resolution radar-rainfall system demonstrated that the geographical variability of storm depths, intensities and durations is significant in the Greater Pittsburgh region (Meeneghan et al., 2004).

\subsubsection{Wastewater Flow Monitoring Program}

The quantification and characterization of the dry and wet weather flow from both the combined and the separate sewered areas and the ability to accurately simulate these flows using the hydrologic/hydraulic models depends upon the availability of accurate monitored wastewater flow data. To quantify and characterize the seasonal variations in the sewer system for both dry weather and wet weather, a network of flow meters is installed in municipal lines near the point of connection to the ALCOSAN system and usually deployed for a 12 month period. The meters are rotated to new sites in new basins on a sequential basis to maximize coverage at a minimal cost. These municipal line meters help quantify the total municipal flow from the combined and separate sewered areas to the point of connection to the ALCOSAN system. In addition, long term meters are deployed in the shallow-cut interceptors and are maintained for an extended period to quantify the regional base waste water flow and seasonal variations in the ground water infiltration over a multi-year period. In all approximately 60 monitoring meters were used at a time on a rotating basis, collecting data at 15 min intervals.

Flow monitoring equipment is susceptible to malfunctions and/or hydraulic conditions which may result in errant and/or missing data. Since the simulation model accuracy is determined relative to observed depth and flow data, any uncertainty or bias in the observed data would be transferred to the model during the validation/verification process. Therefore, an effective quality assurance and quality control (QA/QC) program, both in the field and in the post-collection data review, is implemented to ensure that the data collected and used to support the model is accurate and reliable.

\subsection{Evolution of the Hydrologic/Hydraulic Model}

To help quantify the volume and peak wet weather flow that can be conveyed to the ALCOSAN waste water treatment plant (WWTP) with the proposed future RLTWWCCP conveyance improvements in place, a 
simplified planning level system-wide model was developed. Rather than develop a large, detailed computer model, by building detailed representations of each sewer sub-system, it was preferable to build the model as an evolutionary process, employing the appropriate level of complexity and detail at various stages of the process, to meet various objectives as they evolve. The process began in 1994, as part of supporting the development of the RLTWWCCP, with the development of simplistic Tier-1 models. The development of the Tier-1 models did save ALCOSAN money by distributing the total cost over an extended period, but cost savings was not the primary reason for implementing a tiered or incremental approach. The driving force for the incremental approach was that during the latter half of the 1990s when the Tier-1 models were being developed and applied, the information available from individual service communities was not at a level of refinement and field verification that is consistent with the cost and complexity of Tier-2 modeling. A phased implementation approach maximized cost efficiency by matching the level of model complexity with the pace that refined model input data would become available. With the availability of a significant amount of quality assured flow monitoring data, improved GIS information and better computational capabilities, more detailed planning level system-wide Tier- 2 models have been developed. These detailed Tier-2 models will be used to refine the RLTWWCCP, which should significantly reduce the cost of implementing the plan.

\subsubsection{Preliminary Concept Tier 1 Model}

The Tier-1 model was a simplistic representation of the ALCOSAN flow quantification and conveyance system. The Tier-1 model did not have any runoff hydrology and used scaled ramps at 320 inflow points. These scaled ramps characterized the performance of the ALCOSAN regulator structures and estimated the amount of wet weather flow that can enter the ALCOSAN conveyance system. Once the flows entered the conveyance system, the flows were routed through 880 conduits in the Extended Transport (EXTRAN) block of the United States Environmental Protection Agency's (USEPA) Storm Water Management Model (SWMM) (Huber and Dickinson 1988, and Roesner et al., 1988) to the regional waste water treatment plant. These 880 conduits modeled the shallow-cut and deep tunnel interceptors. The Tier-1 model was a simple concept model that did not perform long-term continuous simulations and produced simple flow exceedance curves to quantify the total flow that the system may generate. 
This simple model was sufficient to meet the goals and objectives of preliminary conceptual planning studies.

\subsubsection{Preliminary Planning Tier-2 Model}

The availability of detailed GIS information of the ALCOSAN service area, a significant quantity of quality assured waste water flow monitoring data, and implementation of the sophisticated radar-rainfall system guided the ALCOSAN authority to the next evolutionary stage of a detailed representation of the hydrology of the system. This representation of system hydrology based on monitored precipitation and flow data significantly reduced the uncertainty in the simulation model results which is associated with the input data. The Tier-2 models are an improvement over the Tier-1 models as they contain detailed hydrology of the area, modeling the wet weather flow including snow melt using 1730 sewersheds in the RUNOFF block of SWMM and continuous time series of dry weather flow based on quality assured flow monitoring data. These flows were then routed to the waste water treatment plant through 617 conduits in the EXTRAN block of SWMM. These 617 conduits modeled the simplified representation of the deep tunnel interceptors and the loading, overflow and connector pipes for the regulator structures at the point of connection to the deep tunnel interceptors. The EXTRAN model was simplified from 880 conduits in Tier-1 to 617 conduits in Tier-2 to reduce the run times of the long-term continuous simulations. The Teir-2 model is a planning level model which can perform long-term continuous simulations and produce time series detailing the time and magnitude of peak flows, to quantify the total flow being generated in the system.

\subsubsection{Facility Planning Tier-2 Model}

The next evolutionary stage of the Tier-2 model is the development of the facility planning system-wide model. In addition to the detailed hydrology and the detailed representation of the dry weather flow, the facility planning model would also model the detailed hydraulics of the regulator structures, control facilities and the waste water pumping station. The facility planning level system-wide model will route the flows from 1730 sewersheds and 387 dry weather flow loading points through approximately 2100 conduits to the waste water treatment plant. The Facility Planning Tier-2 model is being developed on a planning basin approach, modeling in detail one planning 
basin at a time. At the time of developing the Preliminary Planning Tier-2 model, detailed models for $25 \%$ of the planning basins have been developed and the detailed modeling of the remaining planning basins is in progress. The Facility Planning Tier-2 model will be developed when all the planning basins have been modeled in detail. It is expected that this detailed representation of the hydrology and hydraulics of the system will provide a better estimate of the flows that need to be managed, thereby optimizing the design of conveyance and control facilities and mitigating the implementation cost of the RLTWWCCP. The appropriate level of complexity and detail will be applied to the modeling process to match and meet the evolving needs of planning and design.

Table 3.1 presents a comparison of the different modeling metrics for the three models described in this section. This chapter discusses the development and use of the Preliminary Planning Tier-2 model.

Table 3.1 Comparing modeling metrics for the evolving models.

\begin{tabular}{|c|c|c|c|}
\hline $\begin{array}{l}\text { Modeling } \\
\text { Metric }\end{array}$ & $\begin{array}{c}\text { Preliminary Concept } \\
\text { Tier-1 }\end{array}$ & $\begin{array}{l}\text { Preliminary Planning } \\
\text { Tier-2 }\end{array}$ & $\begin{array}{l}\text { Facility Planning Tier- } \\
2\end{array}$ \\
\hline Hydrology & Simplified & $\begin{array}{c}\text { Detailed with } 1730 \\
\text { sewersheds }\end{array}$ & $\begin{array}{l}\text { Detailed with } 1730 \\
\text { sewersheds }\end{array}$ \\
\hline $\begin{array}{l}\text { Hydraulics- } \\
\text { Conduits }\end{array}$ & 880 & 617 & $\sim 2100$ \\
\hline $\begin{array}{l}\text { Hydraulics- } \\
\text { Regulators }\end{array}$ & $\begin{array}{l}\text { None- - Ramped } \\
\text { hydrographs }\end{array}$ & $\begin{array}{l}\text { Hydraulic capacity } \\
\text { estimated external to } \\
\text { SWMM }\end{array}$ & $\begin{array}{l}\text { Detailed dynamic } \\
\text { hydraulic treatment } \\
\text { rates }\end{array}$ \\
\hline $\begin{array}{l}\text { Hydraulics- } \\
\text { Interceptors }\end{array}$ & $\begin{array}{l}\text { All shallow-cut } \\
\text { interceptors and deep } \\
\text { tunnel interceptors }\end{array}$ & $\begin{array}{l}\text { Aggregated shallow-cut } \\
\text { interceptors and detailed } \\
\text { deep tunnel interceptors }\end{array}$ & $\begin{array}{l}\text { Detailed shallow-cut } \\
\text { and deep tunnel } \\
\text { interceptors }\end{array}$ \\
\hline
\end{tabular}

\subsection{Model Validation Effort}

For the simplified preliminary planning system-wide model prepared in support of the planning studies for the expansion of the WWTP, all the simplification is in the representation of the hydraulics of the regulator structures, conveyance systems and the pump operations at the wastewater treatment plant. The representation of the both the dry weather flow and the wet weather hydrology of the system is detailed. The evolutionary refinement of the models is an ongoing process. The dry weather flow is 
updated with the available flow monitoring data and the runoff parameters are updated when new sewersheds are monitored and validated.

Throughout this chapter the term validation is used to describe the process of comparing and modifying the model parameters to match the monitored data. Some professionals recognize this process as calibration. In other approaches for a given number of monitored storm events, a larger portion of the storm events are used to calibrate the model parameters and then the remaining storm events are used to verify the predictive capability of the model. In their analysis the authors considered all the monitored storm events to finalize the model parameters and describe the process as validation. Oreskes et al., 1994, Rykiel Jr., 1996 and Sargent 1998 provide some interesting reading on this topic. This section discusses in brief the methodology followed for the validation of the hydrology and dry weather flow of the system.

\subsubsection{Runoff Validation}

\subsubsection{Separate Sewered Areas}

Rainfall Dependent Inflow and Infiltration (RDII) is the extraneous flow that enters the sewer system and/or the service laterals through system defects. RDII quantities tend to increase rapidly during a storm event and then dissipate gradually to the base flow levels over a period of time depending upon the size of the sewered area and the timing of the storm. The amount of RDII finding its way into the sewer system is dependant upon various factors such as the nature of collection systems, ground water table, etc., which tend to vary from site to site, event to event and season to season. Accurate quantification of RDII is important to the development and refinement of the hydrologic and hydraulic simulation models because excessive RDII can impair the available conveyance capacity of the sewer system and result in increased frequency and duration of excessive surcharge in sewers and $\mathrm{CSO} / \mathrm{SSO}$ discharges. To characterize and quantify the RDII in separate sewered areas, flow monitoring data was analyzed external to SWMM using SHAPE Utilities Programs. SHAPE is a proprietary CDM software program that analyzes the flow monitoring data using a unit hydrograph curve fitting method to formulate a relationship between precipitation and monitored RDII within separate sewered areas. The quality assured and formatted precipitation and flow monitoring data is analyzed by SHAPE through the following three procedures: 
Estimating Dry Weather Flows

This procedure aims to estimate a typical diurnal pattern for total dry weather flow which is the sum of base waste water flow (BWWF) and ground water infiltration (GWI). The analysis selects and keeps days within the monitoring period for which the flows are not influenced by rainfall and excludes those days for which the flows were affected by rainfall and holidays and special events which tend to have a different diurnal pattern. The selected days were averaged to get an average weekday and weekend dry weather flow diurnal pattern that is used in the subsequent procedures.

\section{Hydrograph Decomposition}

This procedure aims to separate the monitored flow into its components: BWWF, GWI and RDII. Based on the assumption that the RDII should be approximately zero before and after the storm event, the GWI was manually adjusted to account for seasonal variations. RDII is then calculated by subtracting the adjusted dry-weather flow from the monitored flow.

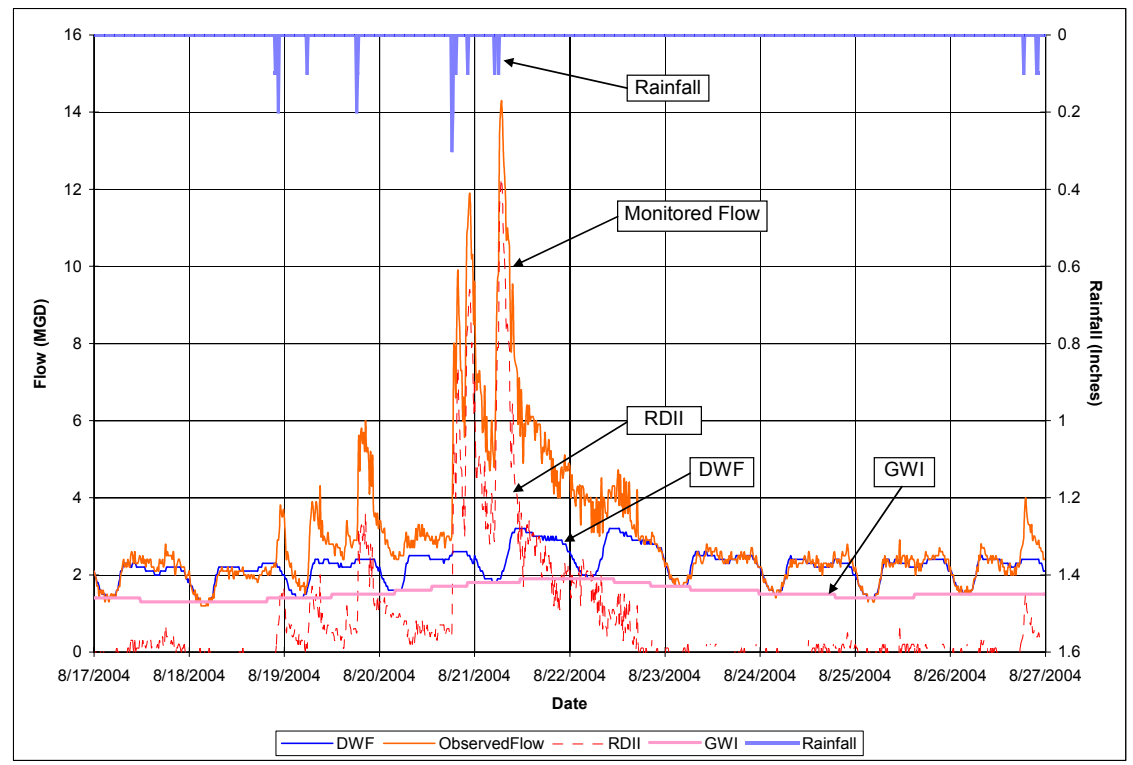

Figure 3.1 Hydrograph decomposition. 
An illustrative example of hydrograph decomposition can be found in Figure 3.1, which shows the monitored waste water flow and its components namely DWF, GWI and RDII. Events can be defined by identifying the start and end time. For each storm event the total rainfall volume, the total RDII volume and the total $R$ value is generated. The total $R$ value for a event is defined as the ratio of the calculated RDII volume to the rainfall volume over the sewershed area expressed as a percentage. For example, a total $\mathrm{R}$ value of 0.07 , would indicate that $7 \%$ of total rainfall volume over the sewershed area made its way into the sewer system as monitored RDII.

\section{Unit Hydrograph Fitting}

The purpose of this procedure is to optimize a set of three unit hydrographs for each storm event to match the simulated RDII hydrograph to the monitored RDII hydrograph. The three unit hydrographs simulate the fast, moderate and slow sewer responses to rainfall.

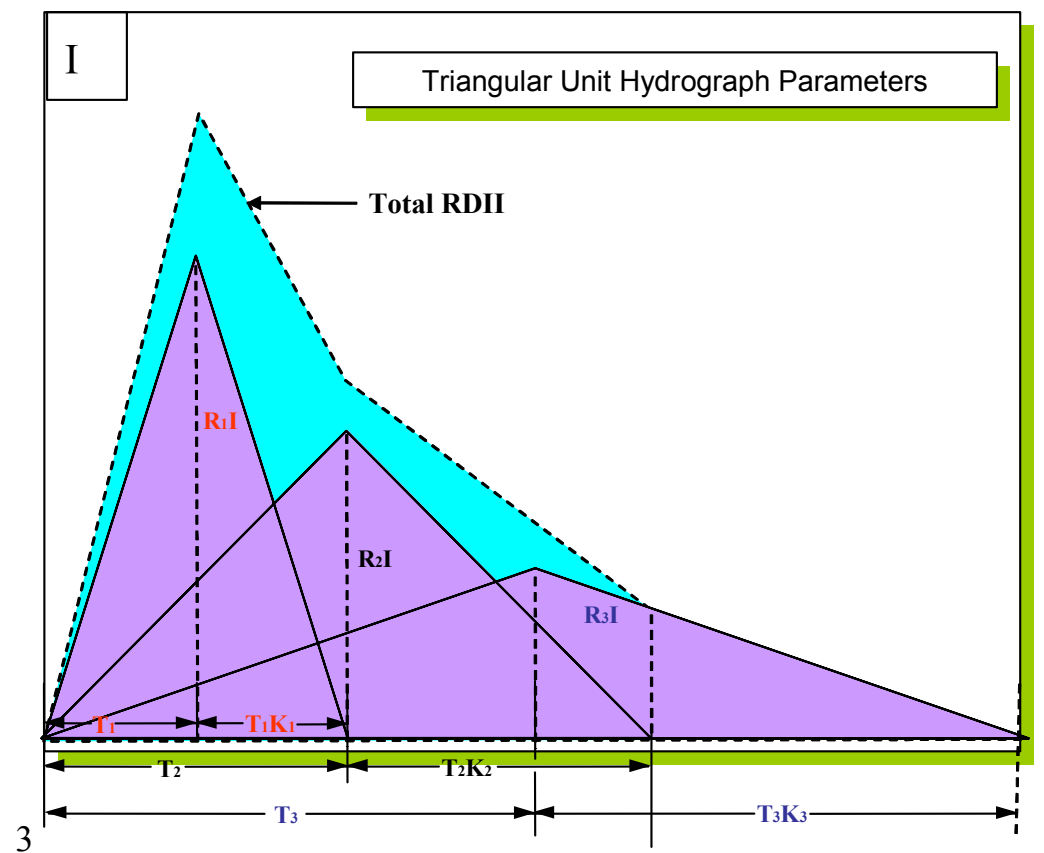

Figure 3.2 Unit hydrograph fitting. 
Each unit hydrograph is characterized by the following three parameters:

$\mathrm{R}$ - the fraction of rainfall that enters the sewer system,

$\mathrm{T}$ - the time to peak in the unit hydrograph (hours), and

$\mathrm{K}$ - the ratio of the recession time to the time to peak

Figure 3.2 illustrates the three unit-hydrographs.

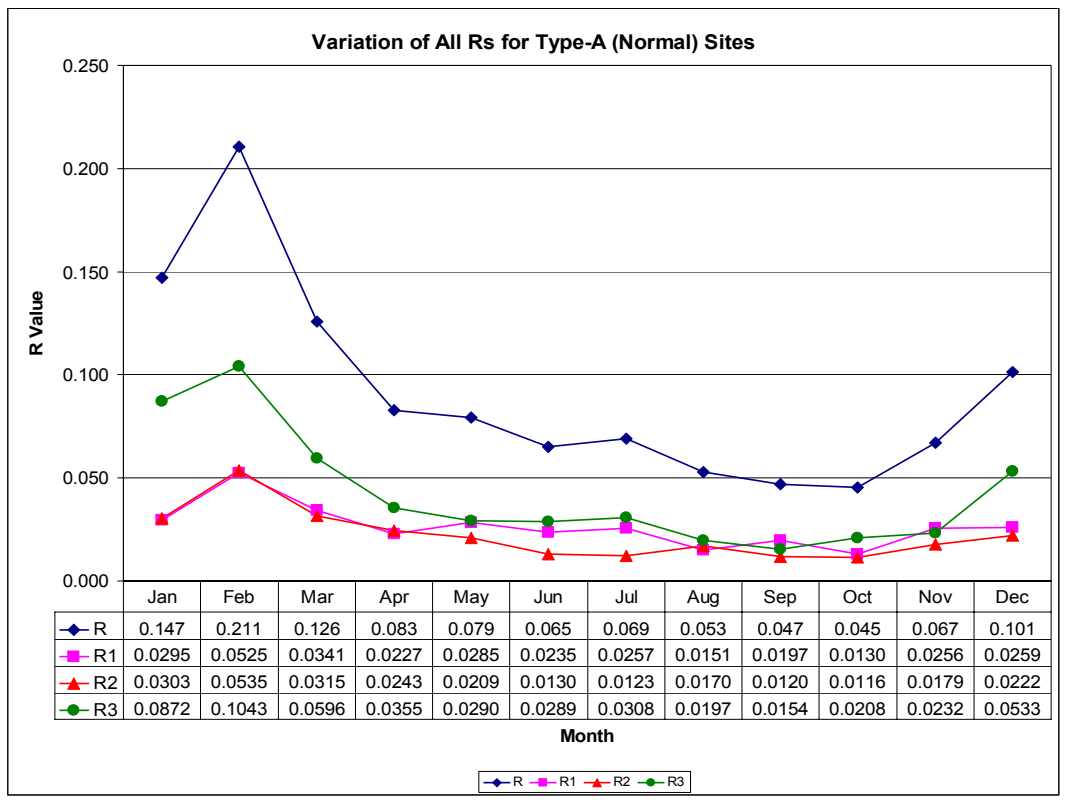

Figure 3.3 Monthly varying $R$ values.

The RTK parameters for each analyzed storm event were adjusted to obtain a good fit. To account for seasonal variation in the RDII responses, the RTK parameters for individual storm events were averaged on a monthly basis. These twelve sets of RTK values were input into SWMM to characterize the wet weather responses from separate sewered areas (Loehlein et al., 2004). An illustrative example of monthly varying $R$ values can be found in Figure 3.3, $\mathrm{R}$ is the total $\mathrm{R}$-value representing the percentage of total rainfall volume over the sewershed area entering the sewer system as monitored RDII, R1 is the R-value for the first unit hydrograph in Figure 3.2 representing the fast system response and the inflow component of the 
monitored RDII, R2 is the R-value for the second unit hydrograph in Figure 3.2 representing the moderate system response and $\mathrm{R} 3$ is the R-value for the third unit hydrograph in Figure 3.2 representing the slow system response and the infiltration component of the monitored RDII.

The selected 12-month monitoring duration for sewersheds served by separate sewers resulted in numerous monitored storm events that can be analyzed. For each of the monitored storm events, the model-simulated peaks and volumes were compared with the monitored storm peaks and volumes. Linear regression plots were prepared to compare the simulated and monitored flows and evaluate the model validation. The regression plots present the goodness of fit for the event volumes and event peaks. For a perfect fit, the trend line drawn through the data points should have a slope of 1.0 and an intercept of 0.0 .

Illustrative examples of the volume and peak regression plots and plot showing the monitored and simulated flows can be found in Figures 3.4, 3.5 and 3.6 respectively.

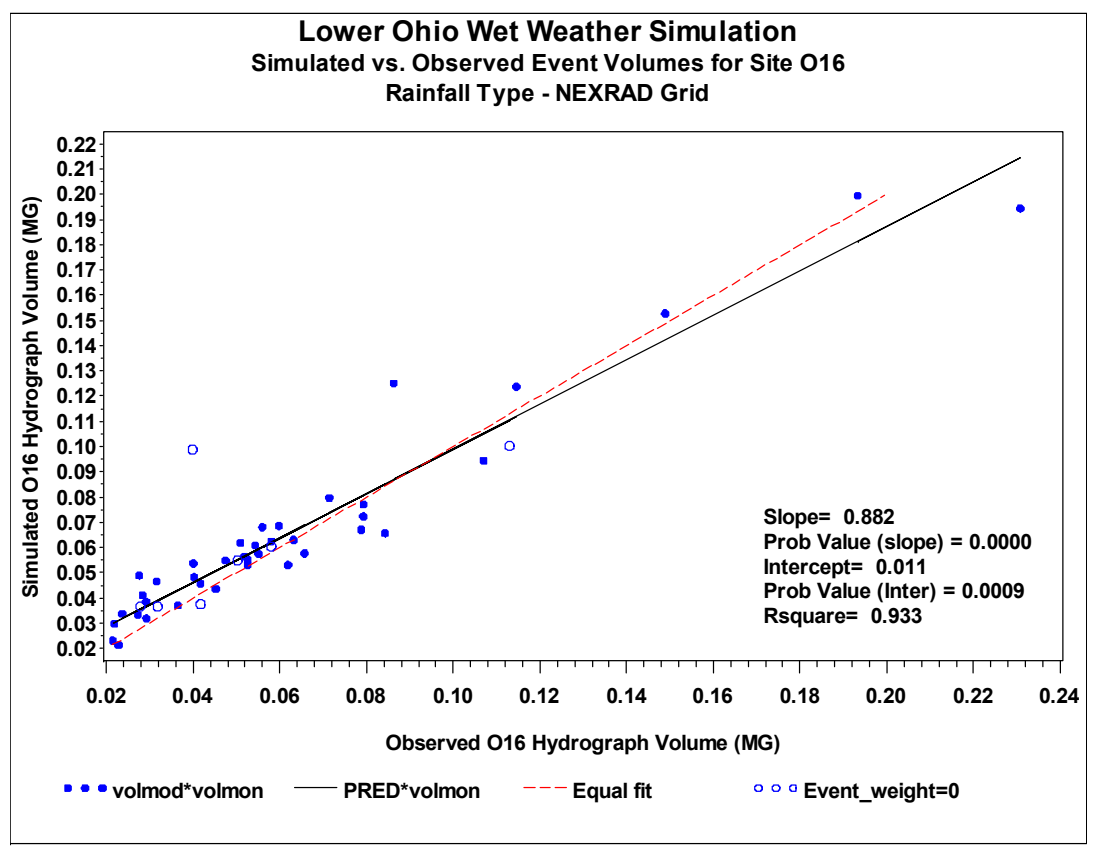

Figure 3.4 Event volumes regression plot. 


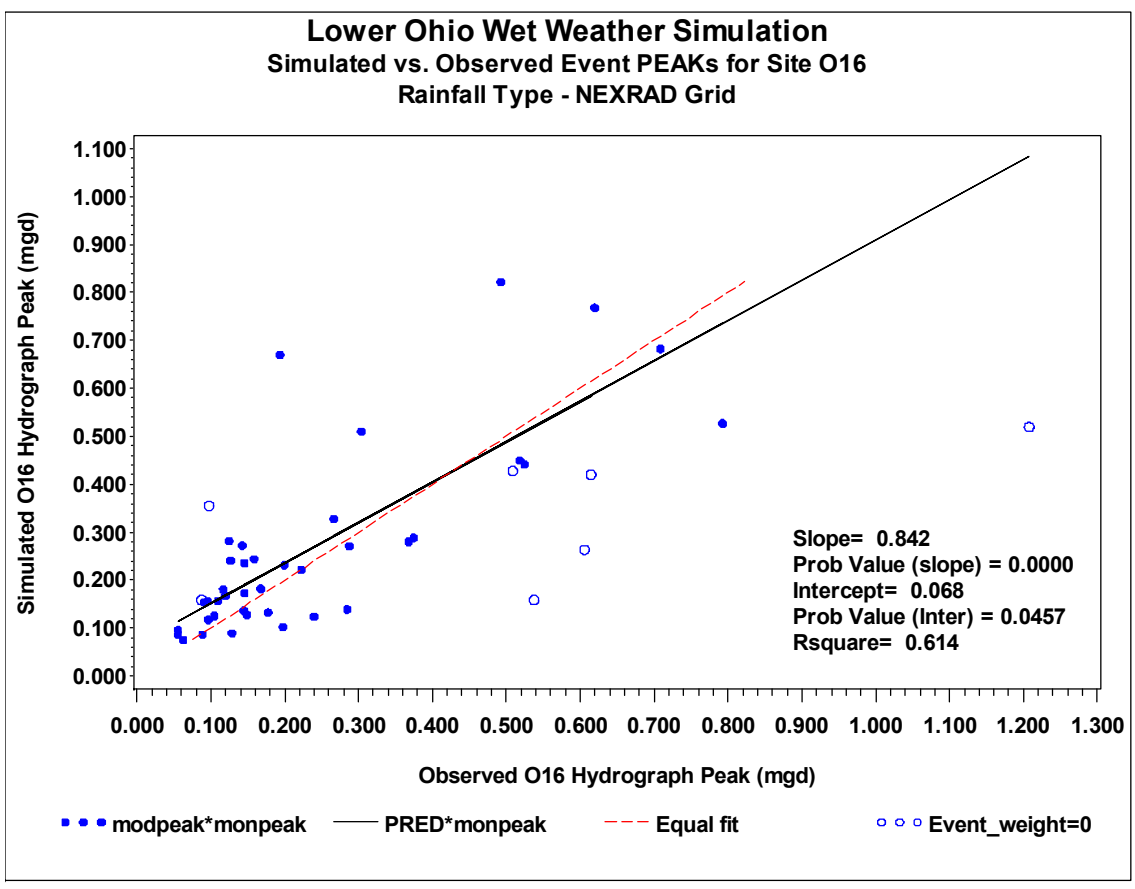

Figure 3.5 Event peaks regression plot.

In Figures 3.4 and 3.5, the filled circles represent the "kept" events while the open circles represent the "outlier" events. Some events were deemed "outliers" either because no reliable monitoring data was available for these events or the simulated results were unreasonable. The "outlier" events were not included in the regression analysis because it would create a bias in the regression plots. In general the scatter in the data points of the event volume regression plots is less than that of the event peaks regression plots, resulting in a higher $\mathrm{R}^{2}$ value for the event volumes regression plots as compared to the event peaks regression plots.

The RTK parameters were developed for 20 selected monitored separate municipal sewersheds based on 22-46 events. For the unmonitored separate sewersheds the RTK parameters were extrapolated based on the monitored sewersheds and drawing similarities between the sewersheds. This level of model complexity, and the corresponding level of effort and cost, was needed to accurately simulate seasonal variation in extraneous ground water 
and surface water entering regional sewer collection systems. This additional model complexity did not induce significant adverse impacts on run time and met the planning need for the expansion of the treatment plant.

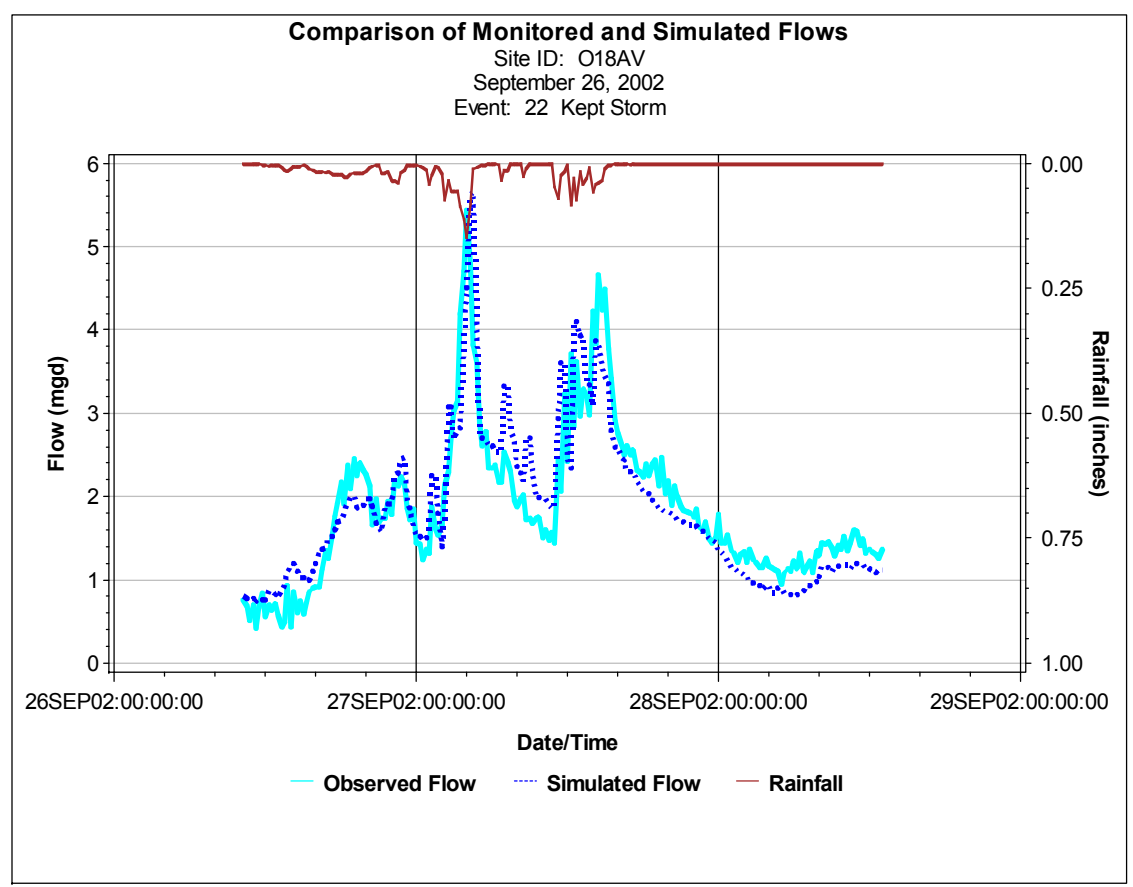

Figure 3.6 Observed and simulated flows.

\subsubsection{Combined Sewered Areas}

Most of the parameters needed to model the combined sewersheds are derived from GIS, including the sewershed area, initial estimate of overland flow lengths and the infiltration parameters based on the soil distribution in the sewersheds. The slopes for the modeled areas are derived from USGS Digital Elevation Model (DEM) for the Pittsburgh area. To better model the recession limb of the storm events, the combined sewershed area was further divided into the pervious area and four slope categories of high slope ( $>5 \%)$, medium slope (between 1\% and 5\%), low slope (between $0 \%$ and $1 \%$ ) and zero slope for the impervious area. Extensive use of GIS to derive the runoff parameters limited the validation parameters to depression storage and directly connected impervious area (DCIA). 
The duration of the monitoring program provides numerous storm events that can be analyzed. For each of the monitored storm events, the modelsimulated peaks and volumes were compared with the monitored storm peaks and volumes. Linear regression plots were prepared to compare the simulated and monitored flows and evaluate the model validation. The regression plots present the goodness of fit for the event volumes and event peaks. For a perfect fit, the trend line drawn through the data points should have a slope of 1.0 and an intercept of 0.0. Regression plots for event volumes and peaks and plots showing the monitored and simulated flows, similar to those in Figures 3.4, 3.5 and 3.6 were generated.

Model parameters were developed for six monitored municipal sewersheds with combined sewers in the planning basins based on 22 to 46 events and for 22 monitored City of Pittsburgh combined sewersheds based on eight events. For the unmonitored combined sewersheds the runoff parameters were extrapolated based on the monitored sewersheds and drawing similarities between the sewersheds. Flow monitoring data was available for a limited number of combined sewersheds to develop the validation parameters and these validation parameters were then extrapolated to the unmonitored sewersheds. To account for the uncertainty in the estimation of the wet weather flow from the combined sewersheds a range was applied to the validation parameters and the model simulation results were also generated as a range of flows.

\subsubsection{Dry Weather Flow Estimation}

The dry weather flow consists of BWWF which is the residential, commercial and industrial flow discharged into the collection system to be conveyed and treated and dry-weather GWI which makes its way into the collection system through cracks in the sewer pipes, leaking laterals, leaking pipe joints and manhole walls during dry weather days.

For the long-term continuous simulation model the dry weather flow was needed as a continuous time-series at various loading points.. Therefore a systematic approach was needed that could be used to extrapolate the monitored data to define a continuous time-series of dry weather flow. The dry weather flow magnitude and pattern was derived from the flow monitoring data as described in section 3.4.1.1 above. The dry weather flow information was derived from flow monitoring locations that fall in three categories: 
1. Municipal trunk sewers that were monitored as part of the ALCOSAN flow monitoring program and had sufficient quantity of quality assured data for analysis. These meters, generally left in place for approximately 12 months, are placed along municipal trunk sewers above their point of connection with the ALCOSAN system. The data obtained from these sites were used to quantify and characterize influent municipal flow to the ALCOSAN system. The dry weather flows derived from these sites were input directly into EXTRAN models at the load point corresponding to the monitored sewershed.

2. Shallow cut interceptor locations that were monitored as part of the ALCOSAN flow monitoring program where quality assured data is available for analysis. These meters have generally been left in place for several years to characterize the way wastewater flow varies from monthto-month, season-to-season and year-to-year. These locations are useful in quantifying and characterizing wastewater flow for large geographical areas during dry weather periods. Dry weather flows derived from these were distributed to the upstream unmonitored sewersheds based upon service population and tributary area.

3. Flow data collected at the ALCOSAN WWTP were used extensively to derive dry weather flows for unmonitored City of Pittsburgh combined sewersheds along the Main Rivers. The WWTP flow data also was used to verify that the total simulated dry weather flows matched the observed conditions at the WWTP.

While compiling the long-term dry weather flow time-series, the BWWF and GWI were determined separately and then combined. For monitored sewersheds, the average weekday and weekend BWWF derived from monitoring data were repeated for the entire extrapolation period. The GWI component for the monitored sewersheds was derived from the long-term and seasonally-varying monitored GWI from downstream shallow-cut monitoring locations. For unmonitored sewersheds the assigned BWWF and GWI were extrapolated from downstream shallow-cut monitoring locations based on service population and tributary area respectively. The extensive use of shallow-cut interceptor monitoring data allowed the seasonally-varying GWI to be represented during the entire long-term simulation period. For approximately $20 \%$ of the City of Pittsburgh 
combined sewersheds the assigned BWWF and GWI were based on limited flow monitoring data and for the unmonitored City of Pittsburgh combined sewersheds the assigned BWWF and GWI were extrapolated from monitored WWTP flow based on service population and tributary area respectively.

\subsubsection{Extraneous Flow Calibration}

The monitored flow at the WWTP was used to verify that the dry and wetweather simulated flows matched the observed conditions at the WWTP. Long-term continuous simulations were performed using the Preliminary Planning System-Wide Model. It was noted that the model performed well simulating the flows during dry weather conditions and for small and medium storm events. However, when the WWTP was operating at existing maximum secondary treatment capacity of approximately $225 \mathrm{mgd}$, for larger wet-weather events the model under-simulated the flows. As Figure 3.7 shows, during and after a wet weather event the simulated flow hydrograph goes below monitored flow hydrograph indicating that the model was simulating flows below the WWTP maximum treatment capacity even before the WWTP recovered and started operating below its maximum capacity. This suggests that the system-wide hydrologic model of the municipal sewersheds and ALCOSAN interceptor system alone was not able to adequately simulate these extended period of high flows. Other impacts to the regional system needed to be identified and taken into account, and additional model adjustments were needed to match the observed flows at the WWTP. It was important to include these additional extraneous flows, and to identify the source and the magnitude of the extraneous flows. The additional extraneous flows were attributed to two potential sources:

- River intrusion into the interceptor system through large flap gates along the main rivers stuck open by debris after large wet weather events.

- Additional GWI from unmonitored City of Pittsburgh combined sewersheds with large deep trunk sewers constructed within former natural stream paths. As illustrated in Figure 3.8, for the monitored larger City of Pittsburgh combined sewersheds the GWI component is approximately $90 \%$ of DWF. Based on this analysis additional GWI was assumed for the unmonitored city sewersheds. 


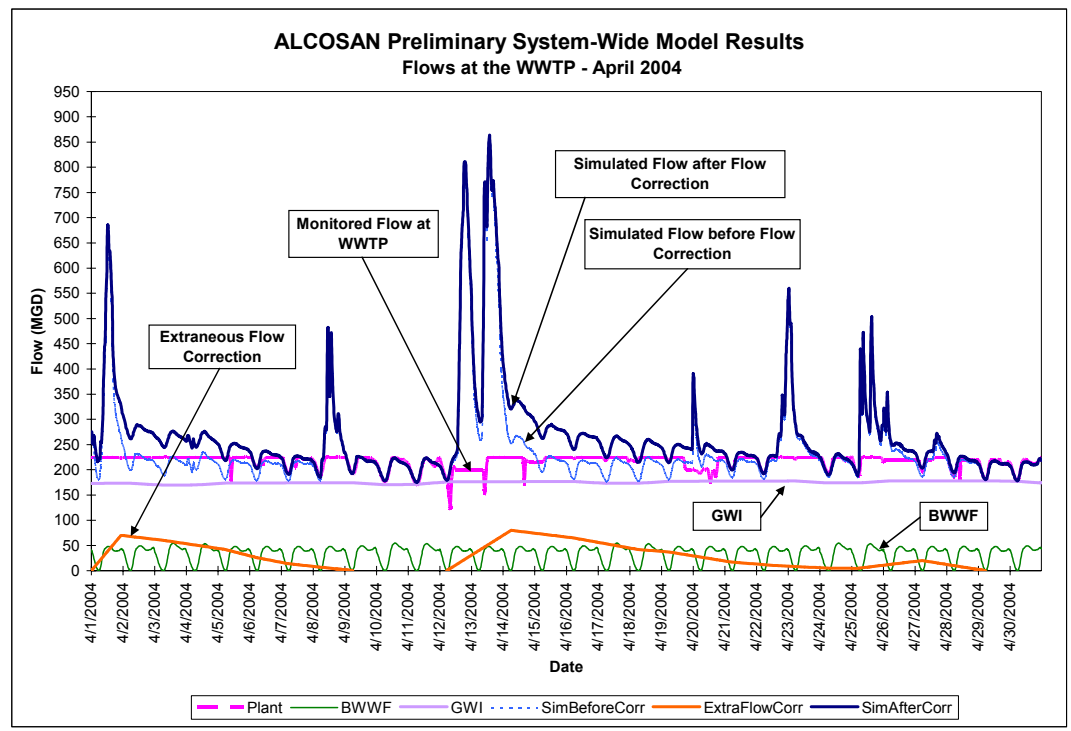

Figure 3.7 Extraneous flow corrections at the WWTP.

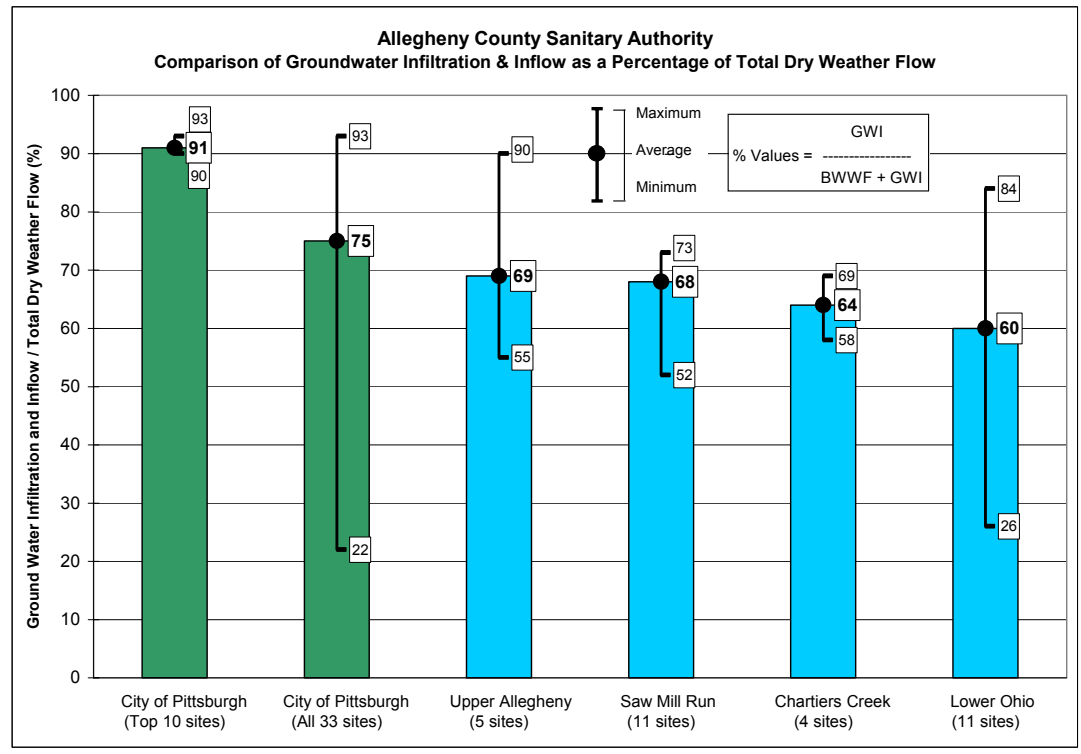

Figure 3.8 Additional GWI from City of Pittsburgh combined sewersheds 
After incorporating model adjustments to take into account these two additional sources of extraneous flow, there was good correlation between simulated and observed flows at the WWTP for the duration of the longterm simulation (illustrated in Figure 3.7).

\subsection{Developing the Simplified Preliminary Planning System-Wide Model}

The objective of developing the simplified preliminary planning systemwide model was to simulate the total flow, both dry weather flow and wet weather flow that needs to be conveyed and treated at the ALCOSAN WWTP, using the best available input information. Since the precipitation and ground water is different from year to year, it was essential to perform a long-term continuous simulation to get a realistic idea of the amount of total flow (both in terms of peak flow and volume) that the WWTP would be required to handle. A period extending 4.5 y between April 2000 and September 2004 was selected for the long-term continuous simulation. Model simulations over this $4.5 \mathrm{y}$ period provide insight into the amount of flow the WWTP has been experiencing in the recent past. This period also coincided with the implementation of the calibrated radar-rainfall program by 3 RWWDP and the period when the majority of the ALCOSAN shallowcut flow monitoring was conducted, thus enabling the optimal use of the available information for model inputs.

The purpose of the planning level system-wide model was to test numerous scenarios to facilitate the decision making process, and hence, the results from the model simulations needed to be made available quickly. The requirement for fast model simulation results necessitated the simplification of the models so that the simulation model run times could be kept sufficiently short. The dry weather flows are quantified external to SWMM and form one part of model inputs. The wet weather flows are generated by the simulation of the hydrologic (RUNOFF) models and the flows thus generated form the second part of model inputs. Both the dry weather flow and the wet weather flow are then routed through the hydraulic elements in the hydraulic (EXTRAN) models. The representation of the flows being generated in the system was detailed, but the routing hydraulics of the conveyance system was simplified to reduce the model run times. The hydraulics of the system was simplified significantly to increase the 
simulation time step from $5 \mathrm{~s}$ to $60 \mathrm{~s}$ while maintaining numerical stability. The simplification of the EXTRAN models was achieved based on the following assumptions:

- The complex pump hydraulics at the WWTP was not simulated. Instead, representative downstream boundary conditions at the WWTP pump station wet-well were implemented so that model conclusions were not affected.

- The conveyance improvements proposed in the RLTWWCCP were implemented with the exception of storage facilities and satellite treatment facilities. These facilities will not have a significant impact on the amount of wet-weather flow captured by the interceptor system and conveyed to the WWTP.

- The deep tunnel interceptors were retained in detail but the shorter segments were combined together to form longer conduits to satisfy the numerical stability criteria for the larger time step.

- The details of the hydraulic network of shallow-cut interceptors were greatly simplified, but flows generated in each individual tributary sewershed were included. These tributary flows were aggregated and loaded at the upstream boundaries of the shallow-cut interceptors. For comparison, Figure 3.9 shows the detailed hydraulic configuration including both deep tunnel and shallow-cut interceptor (the Facility Planning Tier-2 model) and Figure 3.10 shows the simplified hydraulic configuration with simplified shallowcut interceptors.

- The regulator structure hydraulics were simplified and implemented as hydraulic limits the vortex down-shafts and connector pipes. The minimum pipe size for the vortex down-shafts and connector pipes included in the model was 8 -in in diameter. Flows controlled by all regulator structures along the deep tunnel interceptors were included. The hydraulic limits for the vortex down-shafts and connector pipes were estimated external to SWMM by assuming regulator improvements and raising overflow DAM heights. 


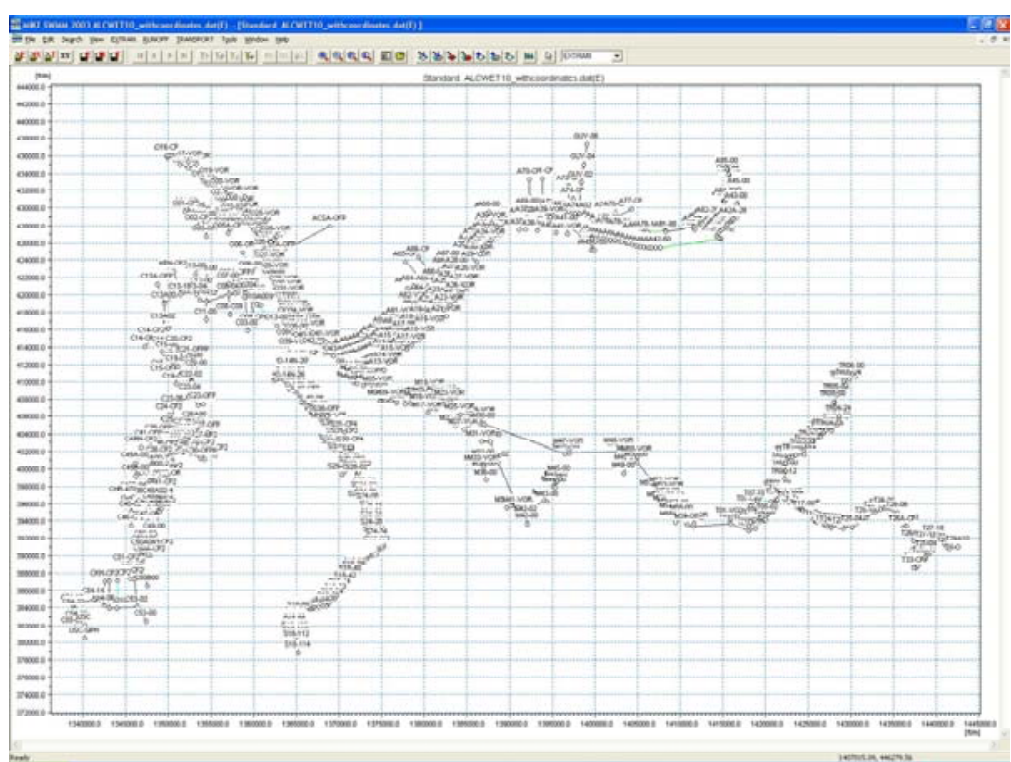

Figure 3.9 Detailed hydraulic configuration

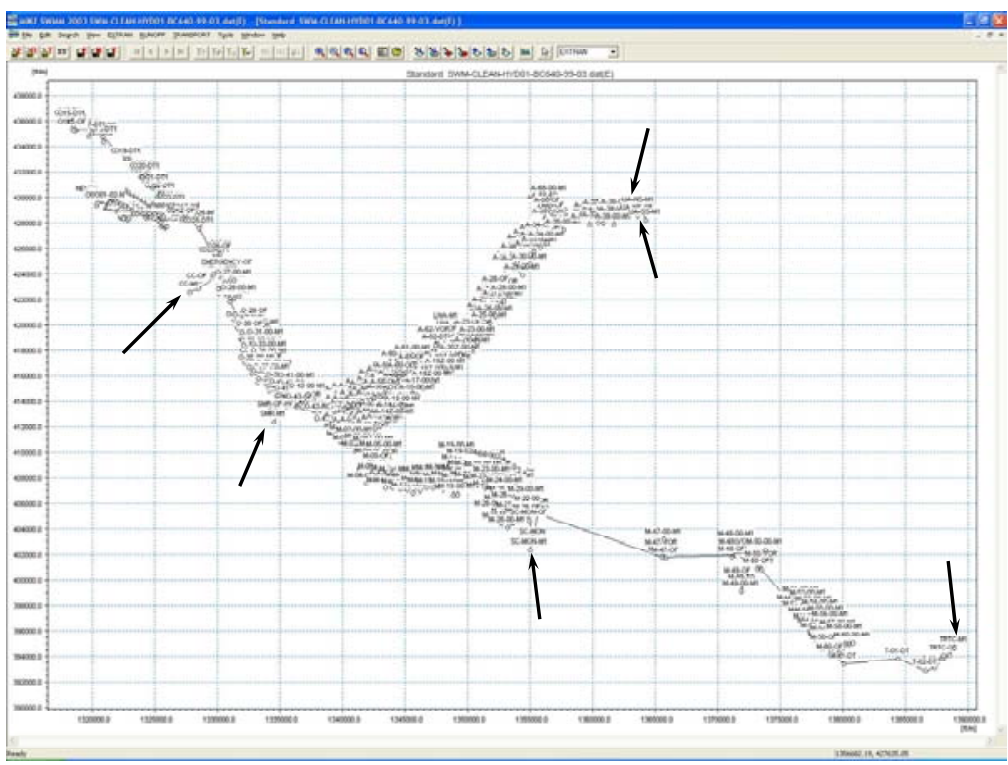

Figure 3.10 Simplified hydraulic configuration 


\subsection{Presenting Results from the Modeling Analyses}

Long-term continuous model simulations were performed over a period of 4.5 y between April 2000 and September 2004. The primary objective of developing the simplified preliminary planning system-wide model was to provide information to guide planning decisions on the expansion of the WWTP by quantifying and characterizing the total flow reaching the plant after implementing the conveyance improvements proposed in the RLTWWCCP. Model simulations resulted in a continuous time-series of total flow reaching the wastewater treatment plant. The simulation results were generated for each constituent year to account for the variation in the total flows over the years. The results were then annualized over $4.5 \mathrm{y}$ to quantify and characterize the average yearly total flows.

An illustrative example of a resulting quarterly time-series is presented in Figure 3.11, and shows the benefits of continuous simulation modeling. Actual monitored storms (high resolution and spatially distributed) were input into the model, and simulation results show the impacts of back-toback storms and the hydrograph recession periods after the storms. This level of model refinement was needed for the planning analysis. The flow time-series was post-processed to develop cumulative distribution function (CDF) graphs of the total flow (Figure 3.12). This CDF curve is used to calculate average annual operating costs at the expanded WWTP. Graphs were also prepared showing the period of exceedance of different flow thresholds (Figure 3.13) and the number of occurrence (frequency) of exceedance of different flow thresholds (Figure 3.14).

The flow frequency and duration estimates for the high end treatment capacity expansions that were considered, i.e. $>850 \mathrm{mgd}$ and $>875 \mathrm{mgd}$ ( $>3210$ and $>3300$ million liters per day), show that to meet water quality objectives of limiting the discharges to 4 to 6 overflows per year, expensive facilities may need to be considered that would be used only a few times per year. These figures show that even with model simplifications, meaningful results can be obtained. It was decided that the hydrograph routing and timing from shallow-cut interceptors is not significant enough to warrant the additional modeling complexity and longer run times as part of this planning phase. However, seasonally variable GWI, monthly variable RDII contributions from separate sewered areas, and spatially distributed highresolution rainfall were significant and could be integrated into the model with only modest increases in run time. It also should be noted that simulation results are not depicted as single values, but as a range of values 
to reflect a reasonable degree of variability and uncertainty in model input parameters that could not be obtained directly from sewershed GIS information.

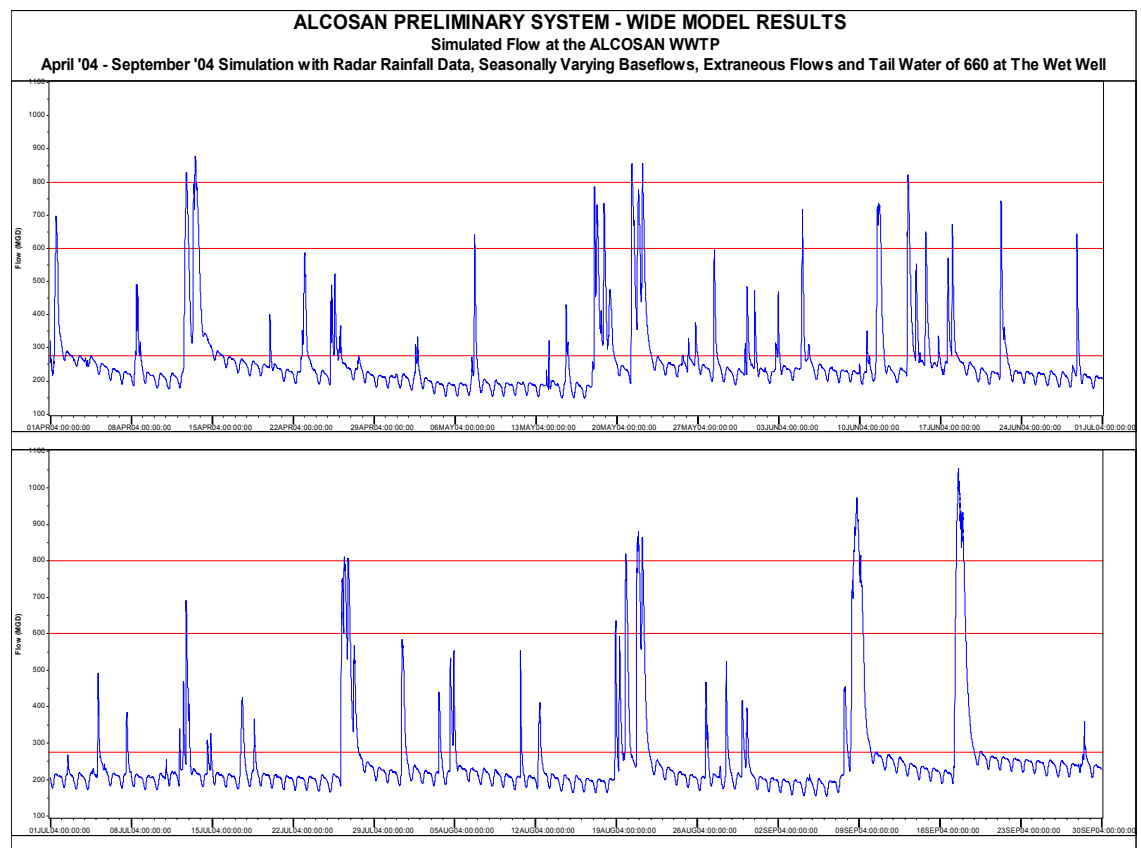

Figure 3.11 Quarterly time-series of total flow

The simulated period covered $4.5 \mathrm{y}$ and the constituent years differed in the amount of precipitation and ground water infiltration. The variation in the annual precipitation is shown in Figure 3.15. The figure also compares the 12-month and 6-month total rainfall with the historical average of total rainfall for these periods. The comparison indicates that the $4.5 \mathrm{y}$ simulation effectively covered the dry, average and wet year conditions. This again reinforces the planning benefits of long-term continuous simulation modeling. A significant degree of variability in rainfall was observed from year to year over the simulation period and resulted in a corresponding range of overflow volumes. A series of single-event synthetic design storms would not be capable of depicting this inter-annual variability. 


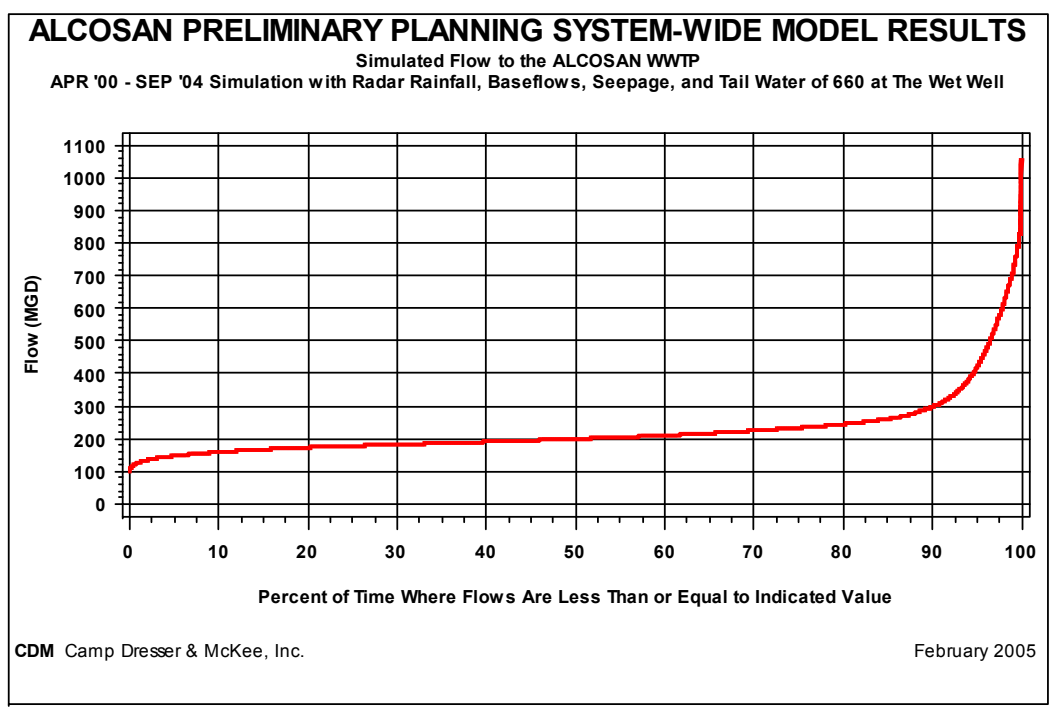

Figure 3.12 Cumulative Distribution Function (CDF) of total flow

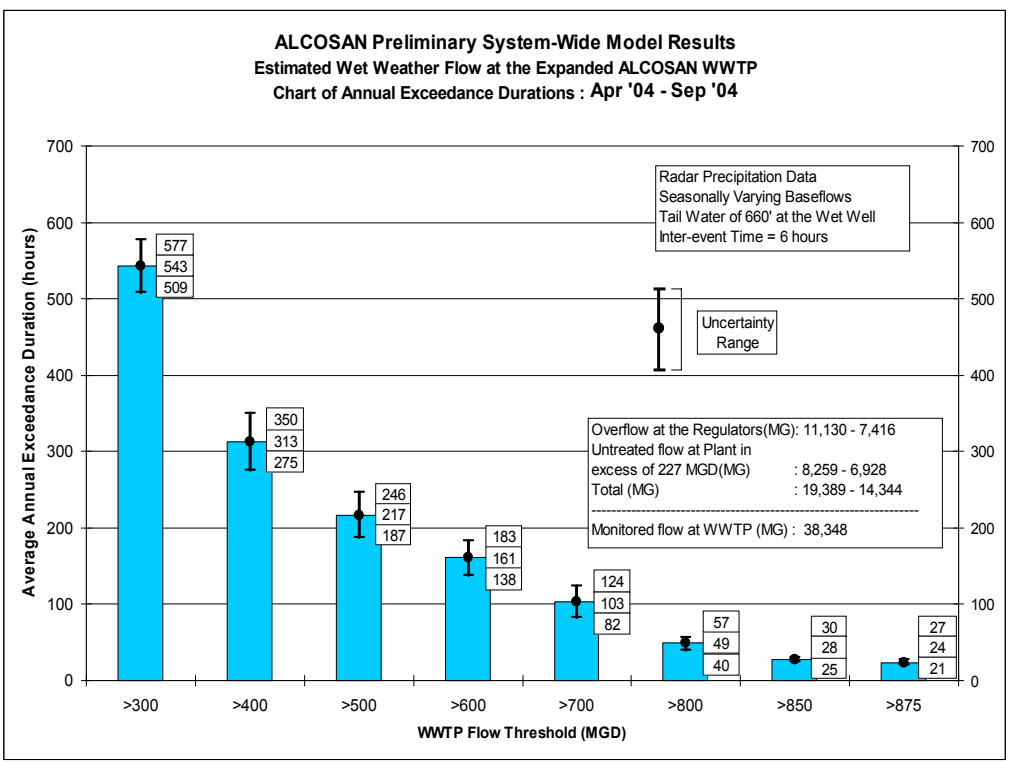

Figure 3.13 Duration of exceedance of flow thresholds 


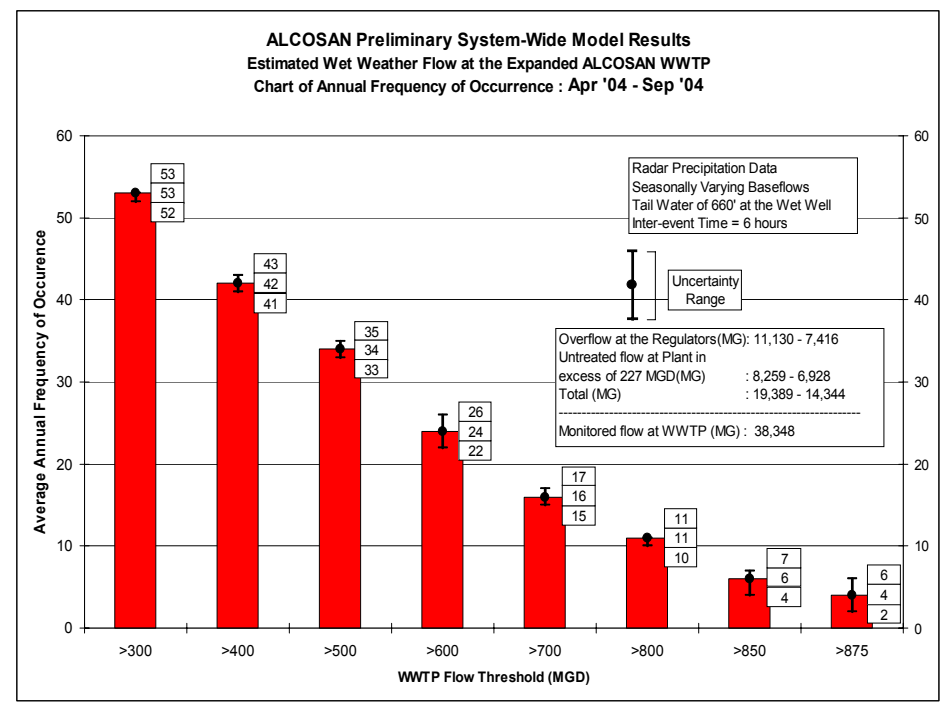

Figure 3.14 Frequency of exceedance of flow thresholds.

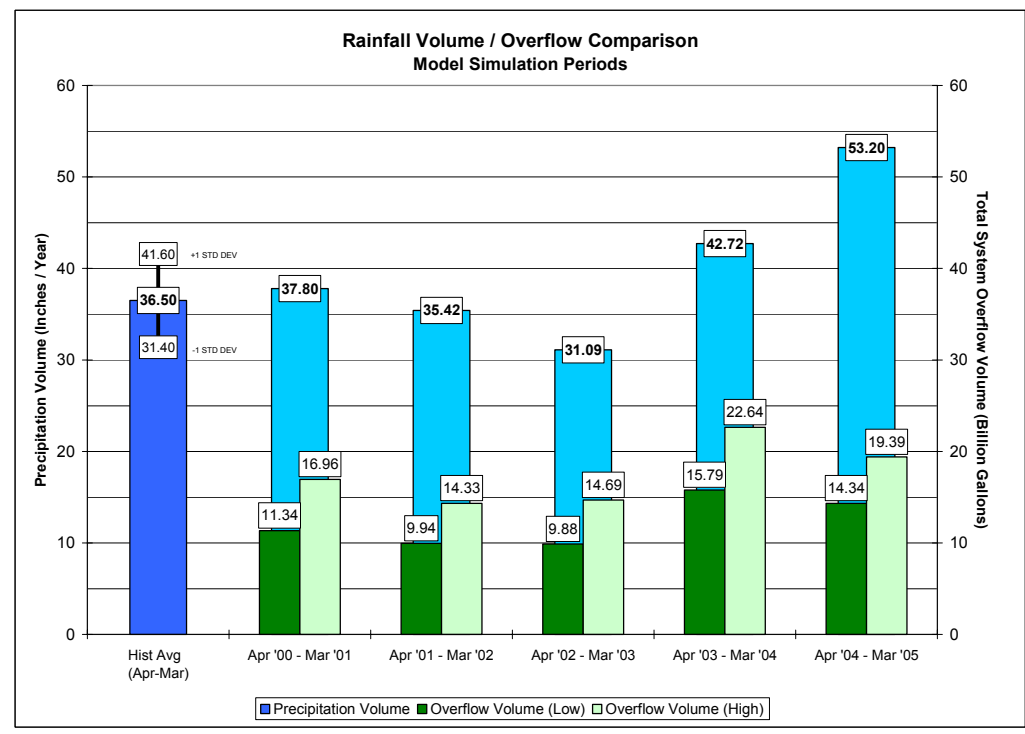

Figure 3.15 Yearly variation of precipitation volume in the service area 


\subsection{Conclusions}

In the greater Pittsburgh area, the ALCOSAN authority has made a significant investment to develop and refine the comprehensive wet weather management program that is intended to control CSO and SSO discharges into the area water bodies and consequently improve the water environment within the service area. The estimated cost of the RLTWWCCP is estimated to be as high as US\$2-3 billion, spread over a 50 y period. In support of this, significant regional investments have been made for precipitation and wastewater flow monitoring data collection, field investigation, GIS mapping and facility design.

Significant improvements were and are still being made to better inventory and characterize the ALCOSAN regional wastewater conveyance and treatment system and the tributary municipal collection systems. Complex hydrologic and hydraulic simulation models have been developed and are in the process of being refined to better quantify and characterize the total flow in the sewer systems and the corresponding CSO and SSO discharges. These models are used to develop, evaluate and select optimal regional facilities needed to manage wastewater flow.

The simplified preliminary planning system-wide model described in this chapter was able to provide the simulation results with sufficient accuracy and precision to meet the planning and decision-making needs of ALCOSAN for the expansion of the waste water treatment plant. The information needed to make the decisions required the use of long-term continuous simulations. A series of single-event synthetic design storms could not have provided enough information to make decisions regarding the wastewater treatment plant expansion. The simplified model sufficed for the current needs, and the level of detail and the associated cost of developing a complex facility planning system-wide model was not required at this time.

The evolutionary modeling approach has allowed ALCOSAN to spreadout the flow monitoring and model development costs over time. The next evolutionary stage of the models would require flow monitoring and validation of the remaining sewersheds, including the detailed hydraulics of all the regulator structures, conveyance and storage facilities, and satellite treatment facilities, to develop the facility planning system-wide models. The long-term continuous simulation of these facility planning models will be used to optimize the different wet weather control facilities to mitigate CSO and SSO discharges and help reduce the cost of implementing the RLTWWCCP. 


\section{References}

Huber, W. C. and R. E. Dickinson (1988). Storm Water Management Model User's Manual - Version 4, U.S. Environmental Protection Agency, Athens, Georgia.

Roesner, L.A., R.E. Dickinson and J.A. Aldrich (1988) Storm Water Management Model User's Manual - Version 4 - Addendum 1 EXTRAN, U.S. Environmental Protection Agency, Athens, Georgia.

Smullen, J., E. Burgess and R.E. Dickinson. 2001. "A Tiered Hydrologic and Hydraulic Modeling System to Satisfy Multiple Objectives in Complex Sewershed Applications." Journal of Water Management Modeling R208-01. doi: 10.14796/JWMM.R208-01

Meeneghan, T., T. Prevost and K. Khan. 2004. "Impacts of Rainfall Data on Model Refinement in Greater Pittsburgh." Journal of Water Management Modeling R223-18. doi: 10.14796/JWMM.R223-18.

Loehlein, M., T. Meeneghan and T. Prevost. 2004. "A Continuous Simulation Approach for Separate Sewered Areas." Journal of Water Management Modeling R223-21. doi: 10.14796/JWMM.R223-21.

Oreskes, Naomi, Kristin Shrader-Frechette and Kenneth Belitz, Verification, Validation and Confirmation of Numerical Models in the Earth Sciences, Science, Feb 4, 1994, ProQuest Education Journals, pg. 641.

Rykiel, Edward J., Jr., Testing Ecological Models: the meaning of validation, Ecological Modeling 90 (1996) pages 229-244.

Sargent, Robert G., Verification and Validation of Simulation Models, Proceedings of the 1998 Winter Simulation Conference, D.J. Medeiros, E.F. Watson, J.S. Carson and M.S. Manivannam, eds. 